\title{
Detection and quantification of long chain fatty acids in liquid and solid samples and its relevance to understand anaerobic digestion of lipids
}

\author{
L. Neves, M.A. Pereira, M. Mota, M.M. Alves* \\ IBB - Institute for Biotechnology and Bioengineering, Center of Biological Engineering, University of Minho, Campus de Gualtar, 4710-057 Braga, Portugal
}

\section{A R T I C L E I N F O}

\section{Article history:}

Received 30 December 2007

Received in revised form 9 June 2008

Accepted 10 June 2008

Available online 27 July 2008

\section{Keywords:}

Long chain fatty acids

Gas chromatography

Anaerobic digestion

Cow manure

\begin{abstract}
A B S T R A C T
A method for long chain fatty acids (LCFA) extraction, identification and further quantification by gas chromatography was developed and its application to liquid and solid samples collected from anaerobic digesters was demonstrated. After validation, the usefulness of this method was demonstrated in a cow manure digester receiving pulses of an industrial effluent containing high lipid content. From the LCFA analysis data it was showed that the conversion of oleic acid, the main LCFA fed to the reactor, by the adapted biomass became faster and more effective along the successive pulses. Conversely, the accumulation of palmitic acid in the solid phase suggests that degradation of this LCFA, under these conditions, is less effective.
\end{abstract}

(c) 2008 Elsevier Ltd. All rights reserved.

\section{Introduction}

In early literature it is suggested that LCFA, produced during hydrolysis of neutral lipids, exert a permanent toxic effect (Angelidaki and Ahring, 1992) and even a bactericidal effect on methanogens (Rinzema et al., 1994). Furthermore, LCFA inhibitory effect on the anaerobic microbial activity, at even low concentrations, has been often reported (Koster and Cramer, 1987; Hananki et al., 1981; Hwu et al., 1996; Lalman and Bagley, 2000, 2001, 2002; Shin et al., 2003). However, in later studies, Alves et al. (2001), observed that after being continuously fed with oleic acid (C18:1), anaerobic sludge that was encapsulated by a whitish matter, was able to efficiently convert to methane the accumulated substrate when incubated in batch assays at $37^{\circ} \mathrm{C}$, without any added carbon source, evidencing that the anaerobic consortium remained active in such conditions. It was further demonstrated that LCFA, provided they are associated with the sludge and not in the bulk medium, can be efficiently converted to methane, besides the observed temporary decrease in the methanogenic activity after the contact with LCFA is a reversible phenomenon, which is eliminated after the conversion to methane of the biomass-associated LCFA (Pereira et al., 2004, 2005). This finding was observed for sludge with specific LCFA contents in the range from 1 to $5 \mathrm{gCOD} / \mathrm{gVSS}$. Therefore, the ability of the encapsulated sludge to efficiently mineralise high amounts of adsorbed/accumulated LCFA may represent a potential challenge to the optimisation of methane production when treating effluents with high lipid/LCFA content. These new reported

\footnotetext{
* Corresponding author. Tel.: +351 253604 4417; fax: +351 253678986 .

E-mail address: Madalena.alves@deb.uminho.pt (M.M. Alves).
}

developments were the driving force to develop a method to identify and quantify the LCFA in the liquid phase as well as accumulated onto the biomass, during the anaerobic digestion process.

Several methods have been developed for extraction and quantification of lipids/LCFA in samples from various sources. Some procedures, adapted to environmental samples, report chloroform, methanol, or a mixture of both as the organic solvent used to extract lipids/LCFA (Bligh and Dyer, 1959). Others procedures include the use of a hexane/methyl tertbutyl ether (MTBE) mixture, as alternative to chloroform-based extractants (carcinogen properties) (Lalman and Bagley, 2004), or other extraction agents such as petroleum ether (Hwu et al., 1998) or heptane (Fernández et al., 2005). In most of the reported methods, the formation of fatty acid methyl esters, by methods similar to those described by Kaluzny et al. (1985), is a routine procedure for subsequent gas chromatography (GC) determination.

Some papers reported results of identification and quantification of LCFA in samples from anaerobic reactors fed with lipids/ LCFA. Nevertheless, these analysis were performed only in the liquid phase or in the centrifuged and filtrate supernatant (Lalman and Bagley, 2000; Hwu et al., 1998; Fernández et al., 2005; Procida and Ceccon, 2006), and not in the solid matrix. Jarvis and Thiele (1997) described a method for extraction of free LCFA from supernatant, biomass and lipid phase for further quantification by high performance liquid chromatography (HPLC). The sample preparation protocol described in this method is complex, including a derivatization step with 2-nitrophenylhydrazine hydrochloride, before HPLC analysis. Hence, a fast and effective method that is able to extract and quantify the LCFA adsorbed onto the solid matrix, i.e. biomass, and present in the liquid phase, i.e. supernatant, 
collected from anaerobic reactors, is required. The extraction of LCFA should be as complete as possible and hydrolysis of neutral lipids should be avoided.

It is important to identify the key intermediates in the lipids anaerobic degradation to full understand the pathways involved in this process, most of the papers about anaerobic digestion of lipids do not identify the LCFA involved (Shin et al., 2003), some only analyse the fat content and report LCFA inhibition (Gebauer and Eikebrokk, 2006).

In this paper, a method for LCFA extraction from liquid and solid samples and further quantification by capillary gas chromatography is described and validated. Furthermore, the application of the developed method to analyse samples of the solid and liquid phases from an anaerobic reactor fed with dairy cow manure during weakly pulses of an oily effluent from a can fish processing industry, is also presented as an example.

\section{Experimental procedures}

\subsection{Standards and reagents}

Lauric (C12:0), myristic (C14:0), pentadecanoic (C15:0), palmitic (C16:0), palmitoleic (C16:1), stearic (C18:0), oleic (C18:1) and linoleic (C18:2) acids (puriss p.a. standard for GC analysis), oleic acid sodium salt (puriss p.a. for GC analysis $\geqslant 99 \%$ ) and dichloromethane (DCM) (puriss p.a. stabilized with amylene) were purchased from Fluka (Buchs, Switzerland). Sodium oleate powder purum (assay of fatty acids min 82\%) was purchased from RiedeldeHäen (Seelze, Gremany) and highly refined olive oil (low acidity) from Sigma (St. Louis, MO, USA). The hydrochloric acid solution (37\%) and 1-propanol (p.a.-ACS) were purchased from Panreac (Barcelona, Spain).

\subsection{Calibration}

Calibration curves were produced from a series of standard solutions $(25,50,100,250,500$ and $1000 \mathrm{mg} / \mathrm{L})$ prepared with the following acids (represented by their chemical notation): C12:0, C14:0, C16:0, C16:1, C18:0, C18:1 and C18:2, in a DCM solution. Pentadecanoic acid (C15:0) was used as the LCFA internal standard (IS).

\subsection{Sample processing}

The standards (DCM solution), liquid (aqueous solution) and solid (anaerobic biomass) samples were submitted to a similar procedure, ensuring that the organic phase and the aqueous phase always comprised equal amount $(3.5 \mathrm{~mL})$, in a total volume of $7 \mathrm{~mL}$. For the standards and liquid samples, once homogenised, $2 \mathrm{~mL}$ were transferred into glass vials. Afterwards, $1.5 \mathrm{~mL}$ of the IS solution (1000 mg/L) and $1.5 \mathrm{~mL}$ of $\mathrm{HCl}$ :1-propanol $(25 \% \mathrm{v} / \mathrm{v})$ were added. For the liquid samples, $2 \mathrm{~mL}$ of DCM was subsequently added, whereas, for the standard solutions, $2 \mathrm{~mL}$ of ultra-pure water was added instead. For the solid samples, a defined amount was transferred to the glass vials and dried for $12 \mathrm{~h}$ at $85^{\circ} \mathrm{C}$. The content of the vial was weighed and the solutions of IS $(1.5 \mathrm{~mL})$, $\mathrm{HCl}$ :1-propanol $(1.5 \mathrm{~mL}), \mathrm{DCM}(2 \mathrm{~mL})$ and ultra-pure water $(2 \mathrm{~mL})$ were further added.

The mixture was vortex-mixed, to promote good contact between the two phases, and was digested at $100{ }^{\circ} \mathrm{C}$ for $3.5 \mathrm{~h}$. After digestion, the content of the vial was transferred with $2 \mathrm{~mL}$ of ultra-pure water to a different vial, rubber covered, and the contact between the two phases was further promoted. These new vials were kept in inverted position for $30 \mathrm{~min}$, after which $1 \mathrm{~mL}$ of the organic phase was collected. $1 \mu \mathrm{L}$ of this sub sample was analysed by GC.

\subsection{Gas chromatography}

This analysis was carried out in a GC system (CP-9001 Chrompack) equipped with a flame ionization detector (FID). LCFA were separated using an eq.CP-Sil 52 CB $30 \mathrm{~m} \times 0.32 \mathrm{~mm} \times 0.25 \mu \mathrm{m}$ column (Teknokroma, Tr-wax), with $\mathrm{He}$ as the carrier gas at $1.0 \mathrm{~mL} \mathrm{~min}^{-1}$. Temperatures of the injection port and detector were 220 and $250{ }^{\circ} \mathrm{C}$, respectively. Initial oven temperature was $50{ }^{\circ} \mathrm{C}$ for $2 \mathrm{~min}$, with a $10^{\circ} \mathrm{C} / \mathrm{min}$ ramp to $225^{\circ} \mathrm{C}$, and a final isothermal for $10 \mathrm{~min}$.

\subsection{Validation procedure}

The presented method was validated in terms of linearity, limit of detection and quantification, precision, accuracy and selectivity. Linearity was evaluated by the correlation coefficient of the calibration curves obtained. Detection limit and quantification limit were estimated as the LCFA concentration for which the area of the chromatographic peak was equal to 3 and 10 times, respectively, the standard deviation of the most diluted standard.

Precision of the method was evaluated using two criteria: reproducibility and repeatability (Miller and Miller, 1993; Caulcutt and Boddy, 1983). According to Castillo and Castells (2001), precision results are reported as relative standard deviation (RSD, \%), which should not exceed the $20 \%$ (Shah et al., 1992). Reproducibility of the method was evaluated by the RSD of the slope of 5 calibration curves constructed over a year period by 3 different analysts $(3+1+1)$. Repeatability (measured as \% RSD) and accuracy (measured concentration/real concentration $\times 100$ ) were assessed by means of LCFA recovery experiments performed in liquid and solid samples. Blank samples (supernatant and biomass from anaerobic reactors) with and without the addition of LCFA were also processed to test for interferences of the liquid and solid biological matrices, evaluating the selectivity of the method. Unwanted hydrolyses of neutral lipids during the LCFA extraction procedure was also evaluated by processing solutions containing olive oil.

An additional series of experiments was carried out to optimise the extraction of the LCFA from the solid phase to the organic phase. Different digestion times, different volumes of the organic phase and different amounts of dry sample were tested.

Tables 1 and 2 summarize the assays performed with liquid and solid samples, respectively. The solid samples consisted of anaerobic suspended $(S)$ and granular $(G)$ biomass collected from three different reactors: (i) a lab scale reactor fed with sodium oleate, designated as biomass SL, which was expected to have a high amount of adsorbed/accumulated LCFA, because it was visibly encapsulated by a whitish matter; (ii) two wastewater treatment plants, designated as biomass S1 and S2; and (iii) an UASB (upflow anaerobic sludge blanket) reactor treating effluent from a brewery company (Oporto, Portugal), designated as biomass G.

\subsection{Statistical analysis}

Single factor analysis of variances (ANOVA) was used to determine if significant differences existed between results obtained under different experimental procedures. Statistical significance was established at the $P<0.05$ level.

\subsection{Application of the method to monitor anaerobic digestion of lipids}

A 26 L mesophilic continuously stirred tank reactor (CSTR) was fed with dairy cow manure (1.4 gCOD/gTS) for 122 days, at an organic loading rate of $1.2 \mathrm{gCOD} /($ Lday). The hydraulic retention time (HRT) was set at 26 days. From day 123 on, pulses of an oily effluent from a can fish processing industry $(2.7 \mathrm{gCOD} / \mathrm{gwaste}$ and 
Table 1

Assays performed to validate the method for liquid (l) samples

\begin{tabular}{|c|c|c|c|c|c|c|c|}
\hline Assay \# & Oleic acid sodium salt (mg/L) & Sodium oleate powder $(\mathrm{mg} / \mathrm{L})$ & LCFA mixture $^{\mathrm{a}}(\mathrm{mg} / \mathrm{L})$ & Olive oil (mg/L) & $\mathrm{C} 16: 0(\mathrm{mg} / \mathrm{L})$ & $\mathrm{C} 18: 1(\mathrm{mg} / \mathrm{L})$ & Solvent \\
\hline $1(1)$ & - & - & $\cong 500$ & - & - & - & Water \\
\hline $2(1)$ & - & - & $\cong 1000$ & - & - & - & Water \\
\hline $3(1)$ & 258 & - & - & - & - & - & Water \\
\hline $4(1)$ & - & 590 & - & - & - & - & Water \\
\hline $5 A(1)$ & - & - & - & - & - & - & Supernatant \\
\hline $5 \mathrm{~B}(\mathrm{l})$ & - & - & $\cong 500$ & - & - & - & Supernatant \\
\hline $6(1)$ & - & - & - & 1173 & - & - & Dichloromethane \\
\hline 7 (1) & - & - & - & 1516 & 938 & 1184 & Dichloromethane \\
\hline
\end{tabular}

${ }^{a} \mathrm{C} 12: 0, \mathrm{C} 14: 0, \mathrm{C} 16: 0, \mathrm{C} 16: 1, \mathrm{C} 18: 0, \mathrm{C} 18: 1$ and C18:2.

Table 2

Assays performed to optimise and validate the method for solid (s) samples

\begin{tabular}{llllll}
\hline Assay \# & Biomass & $\begin{array}{l}\text { Total solids } \\
(\mathrm{g})\end{array}$ & $\begin{array}{l}\text { Digestion } \\
\text { time }(\mathrm{h})\end{array}$ & $\begin{array}{l}\text { Volume organic } \\
\text { phase }(\mathrm{DCM})(\mathrm{mL})\end{array}$ & $\begin{array}{l}\text { Added LCFA }^{\mathrm{b}} \\
(\mathrm{mg})\end{array}$ \\
\hline $1(\mathrm{~s})$ & $\mathrm{SL}^{\mathrm{a}}$ & $\cong 0.05$ & 3.5 & 3.5 & - \\
$2(\mathrm{~s})$ & $\mathrm{SL}$ & $\cong 0.05$ & 5 & 3.5 & - \\
$3(\mathrm{~s})$ & $\mathrm{SL}$ & $\cong 0.05$ & 7 & 3.5 & - \\
$4(\mathrm{~s})$ & $\mathrm{SL}$ & $\cong 0.05$ & 3.5 & 4.0 & - \\
$5(\mathrm{~s})$ & $\mathrm{SL}$ & $\cong 0.05$ & 3.5 & 4.5 & - \\
$6(\mathrm{~s})$ & $\mathrm{SL}$ & $\cong 0.1$ & 3.5 & 3.5 & - \\
$7(\mathrm{~s})$ & $\mathrm{SL}$ & $\cong 0.5$ & 3.5 & 3.5 & - \\
$8(\mathrm{~s})$ & $\mathrm{S} 1^{\mathrm{a}}$ & $\cong 0.05$ & 3.5 & 3.5 & - \\
$9(\mathrm{~s})$ & $\mathrm{S} 1$ & $\cong 0.1$ & 3.5 & 3.5 & - \\
$10(\mathrm{~s})$ & $\mathrm{S} 1$ & $\cong 0.2$ & 3.5 & 3.5 & - \\
$11 \mathrm{~A}(\mathrm{~s})$ & $\mathrm{G}^{\mathrm{a}}$ & $\cong 0.05$ & 3.5 & 3.5 & $\cong 1$ \\
$11 \mathrm{~B}(\mathrm{~s})$ & $\mathrm{G}$ & $\cong 0.05$ & 3.5 & 3.5 & - \\
$12 \mathrm{~A}(\mathrm{~s})$ & $\mathrm{S} 2^{\mathrm{a}}$ & $\cong 0.05$ & 3.5 & 3.5 & $\cong 1$ \\
$12 \mathrm{~B}(\mathrm{~s})$ & $\mathrm{S} 2$ & $\cong 0.05$ & 3.5 & 3.5 & \\
\hline
\end{tabular}

a SL - highly loaded with biomass-associated LCFA; S1 and S2 - suspend sludge from two different wastewater treatment plants; $G$ - granular sludge from a UASB reactor treating brewery wastewater.

b C12:0, C14:0, C16:0, C16:1, C18:0, C18:1 and C18:2.

$99.8 \%$ of fat content) were added once a week, every 7 days. In those days, the organic loading rate applied to the reactor was of $5.0 \mathrm{gCOD} /($ Lday). Chemical oxygen demand (COD) and total solids (TS) were determined according to Standard Methods (APHA, 1989). The fat content from the oily effluent was extracted with a mixture chloroform:methanol $1: 2(\mathrm{v} / \mathrm{v})$ in a soxtec system, dried and weighed.

Samples from the biomass and liquid phase (supernatant) were collected from the bottom of the reactor and analysed for LCFA content. The cow manure and oily effluent fed to the reactor were also analysed for LCFA.

\section{Results and discussion}

\subsection{Calibration and validation}

The tested LCFA were detected by gas chromatography in a 25 min single run analysis, with a good separation between peaks.

The generated calibration curves were linear over the concentration range studied with coefficients of correlation $\geqslant 0.997$ for all the analysed LCFA. Examples of the typical regression equations obtained are shown in Table 3, as well as the correspondent LCFA linear ranges, detection (LOD) and quantification limits (LOQ). Reproducibility was further evaluated by constructing 5 calibration curves over one year period by 3 different analysts. The relative standard deviation of the slopes of the calibration curves generated for each LCFA, ranged between $4.1 \%$ and $13.3 \%$ (Table 3 ), verifying the day-to-day precision of the method. The described LCFA extraction and quantification procedure was further validated for application to liquid and solid samples.
Table 4 presents the results obtained from the recovery assays carried out with liquid samples (Table 1 ). Satisfactory yields were achieved in the tests performed to evaluate the extraction of LCFA from the aqueous phase. Mean recoveries in the range of 91-101\% and $99-110 \%$ were obtained at LCFA concentration levels of about 500 (assay 1(l)) and $1000 \mathrm{mg} / \mathrm{L}$ (assay 2(1)), respectively, with good precision $\operatorname{RSD}_{(500)}<9.5 \%$ and $\left.\mathrm{RSD}_{(1000)}<3.0 \%\right)$. A high mean recovery of oleic acid (C18:1), i.e. 99\%, was also attained from aqueous solutions prepared with oleic acid sodium salt (puriss p.a. $\geqslant 99 \%$ ), with a RSD value of $1.9 \%$ (assay $3(1)$ ). Furthermore, analysis of a solution prepared with sodium oleate powder (assay 4(1)) revealed that oleic acid represented $80 \pm 1 \%$ of the total LCFA detected, which corresponds to a mean recovery of $98 \%$ in relation to the minimum $82 \%$ of $C 18: 1$ expected, as specified by the manufacturer.

Supernatant samples, collected from an anaerobic reactor, with and without the addition of LCFA were also analysed to test for interferences of the liquid biological matrix. No LCFA was detected in the pure supernatant samples (assay $5 \mathrm{~A}(1)$ ). After processing these samples supplemented with the standard LCFA at a concentration level of about $500 \mathrm{mg} / \mathrm{L}$ (assay $5 \mathrm{~B}(\mathrm{l})$ ), mean recoveries above $96 \%$ and RSD lower than $9.0 \%$ were obtained. Additionally, comparison of the chromatograms obtained after processing the matrix solution, i.e. supernatant (assay $5 \mathrm{~A}(1)$ ), and the matrix solution to which the LCFA had been added (assay $5 B(1)$ ) revealed no interferences of the biological liquid matrix in the LCFA analysis (not shown).

Olive oil solutions were also analysed to ensure that the method procedure did not promote hydrolysis of neutral lipids. The obtained results confirmed the desired condition, as no free LCFA were detected after processing the pure olive oil solutions (assay 6(1)). Moreover, high oleic (unsaturated LCFA, C18:1) and palmitic acid (saturated LCFA, C16:0) recoveries were achieved after processing olive oil solutions supplemented with the two acids (assay $7(1))$.

Table 5 presents the results obtained in the assays carried out with solid samples (Table 2), i.e. anaerobic biomass. First, to optimise LCFA extraction from the solid matrix, different digestion times, volumes of organic phase and amounts of dry sample were studied, using biomass expected to be highly loaded with biomassassociated LCFA, designated as SL (assays 1(s)-7(s)). No statistically significant differences at a 0.05 level $(P=0.075)$ were observed when a dry amount of $\cong 0.05 \mathrm{~g}$ of this biomass was submitted to different digestion times of 3.5 (assay 1(s)), 5 (assay $2(\mathrm{~s})$ ) and $7 \mathrm{~h}$ (assay 3(s)). Likewise, when tested for different organic phase volumes of 3.5 (assay 1(s)), 4.0 (assay 4(s)) and $4.5 \mathrm{~mL}$ (assay $5(\mathrm{~s})$ ), the detected LCFA content showed statistic similar results $(P=0.429)$. Furthermore, in all experiments the amount of palmitic acid (C16:0) detected represented $86 \pm 1 \%$ of the total LCFA extracted. However, when the amount of dry biomass was increased to $\cong 0.1 \mathrm{~g}$ (assay $6(\mathrm{~s})$ ) and $\cong 0.5 \mathrm{~g}$ (assay $7(\mathrm{~s})$ ) a decrease on the LCFA content detected to $30 \%$ and $85 \%$, respectively, was found. Nevertheless, in both cases, the percentage of 
Table 3

Parameters from the calibration curves obtained for the analysed LCFA

\begin{tabular}{|c|c|c|c|c|c|c|}
\hline LCFA & Regression equation $^{a}$ & $r^{2}$ & Linear ranges $(\mathrm{mg} / \mathrm{L})$ & LOD (mg/L) & LOQ (mg/L) & RSD of slope $(n=5)(\%)$ \\
\hline $\mathrm{C} 12: 0$ & $y=1.095 x-0.008$ & 0.999 & $25.0-1001.0$ & 5.0 & 16.6 & 13.3 \\
\hline C14:0 & $y=1.039 x+0.003$ & 0.999 & $25.6-1024.0$ & 4.0 & 13.3 & 5.4 \\
\hline C16:0 & $y=0.949 x+0.014$ & 1.000 & $27.7-1108.0$ & 10.4 & 34.6 & 5.2 \\
\hline C16:1 & $y=0.863 x+0.004$ & 1.000 & $31.7-1270.0$ & 7.2 & 24.0 & 5.4 \\
\hline C18:0 & $y=0.879 x+0.016$ & 0.999 & $23.1-925.0$ & 14.4 & 48.1 & 4.1 \\
\hline C18:1 & $y=0.885 x+0.019$ & 0.999 & $27.9-1118.0$ & 14.7 & 49.1 & 7.2 \\
\hline C18:2 & $y=0.794 x-0.014$ & 0.997 & $48.1-961.0$ & 24.2 & 80.7 & 9.6 \\
\hline
\end{tabular}

LOD - limit of detection; LOQ - limit of quantification; RSD - relative standard deviation.

${ }^{a} y=$ LCFA peak area/IS peak area, $x=$ [LCFA]/[IS], IS - internal standard (C15:0).

Table 4

Mean detected LCFA concentrations, relative standard deviation (RSD) and mean recoveries obtained in the validation assays performed with liquid (I) samples

\begin{tabular}{|c|c|c|c|c|c|c|c|}
\hline \multirow[t]{2}{*}{ Assay \# $(n=4)$} & \multicolumn{7}{|c|}{ Detected concentration (mg/L), [RSD (\%)], (recovery (\%)) } \\
\hline & $\mathrm{C} 12: 0$ & C14:0 & $\mathrm{C} 16: 0$ & C16:1 & C18:0 & C18:1 & C18:2 \\
\hline $1(1)$ & 437, [9.5], (94) & $518,[1.1],(94)$ & $341,[1.5],(94)$ & $414,[4.3],(92)$ & $346,[3.2],(99)$ & 547, [2.7], (91) & $375,[1.9],(101)$ \\
\hline $2(1)$ & $935,[1.5],(100)$ & 1187, [1.0], (107) & $745,[0.8],(102)$ & $902,[0.7],(100)$ & $765,[3.0],(109)$ & $1195,[2.2],(99)$ & $820,[2.3],(110)$ \\
\hline $3(1)$ & ND & ND & ND & ND & ND & 237, [1.9], (99) & ND \\
\hline $4(1)$ & ND & $21,[19.2]$ & $33,[14.3]$ & $16,[18.4]$ & $13,[2.3]$ & $331,[6.8],(98)^{a}$ & ND \\
\hline $5 A(1)$ & ND & ND & ND & ND & ND & ND & ND \\
\hline $5 B(1)$ & $480,[5.9],(106)$ & $537,[4.9],(100)$ & $486,[5.0],(105)$ & $646,[5.2],(100)$ & 431, [3.3], (96) & 564, [9.0], (96) & $550,[7.7],(111)$ \\
\hline $6(1)$ & ND & ND & ND & ND & ND & ND & ND \\
\hline $7(1)$ & ND & ND & $981,[1.6],(105)$ & ND & ND & $1332,[3.8],(112)$ & ND \\
\hline
\end{tabular}

ND - non-detectable.

a Percentage of $\mathrm{C} 18: 1$ recovered in relation to a minimum of $82 \%$ of $\mathrm{C} 18: 1$ in the total LCFA present, expected in the sodium oleate powder, as specified by the manufacturer.

Table 5

Mean detected LCFA contents, relative standard deviation (RSD) and mean recoveries obtained in the validation assays performed with solid (s) samples

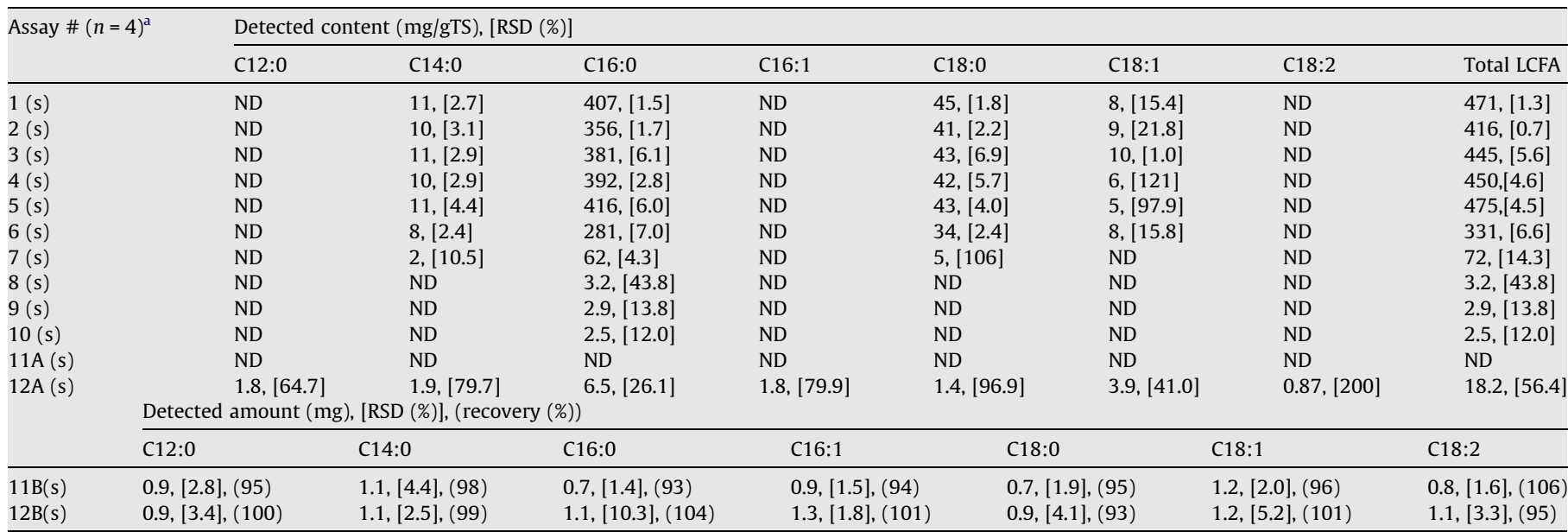

ND - non-detectable.

a Assays 1-7, $n=3$.

C16:0 detected in the total LCFA extracted was identical, i.e. $85 \pm 1 \%$. From the obtained results, the solid phase LCFA extraction procedure was set-up with $3.5 \mathrm{~h}$ of digestion and $3.5 \mathrm{~mL}$ of organic phase, as previously established for the liquid phase extraction procedure. The amount of dry biomass used in this analysis should be such that allows complete LCFA extraction from the solid phase to the organic phase, therefore depending on the amount of LCFA present in the sample. For highly LCFA loaded biomass, i.e. up to a maximum of approximately $500 \mathrm{mgLCFA} / \mathrm{gTS}$, as observed for biomass SL, it was found that a dry amount as low as $0.05 \mathrm{~g}$ was needed in order to avoid LCFA extraction saturation. Due to the heterogeneity associated to the random LCFA accumulation into the biomass, high standard deviations were obtained when analysing the biomass samples.

To validate the lower sensitivity of the method, biomass expected to have a low LCFA content, designated as S1, was also tested using different amounts of dry sample (assays $8(\mathrm{~s})-10(\mathrm{~s})$ ). The results obtained showed no statistically significant differences $(P=0.609)$ in the LCFA content detected when analysing dry amounts of $0.05,0.1$ or $0.2 \mathrm{~g}$, further demonstrating that the described method was feasible even when the biomass has a total LCFA content as low as $3 \mathrm{mg} / \mathrm{gTS}$. In this case, it was found that dry sample amounts higher than $0.05 \mathrm{~g}$ were needed in order to increase the obtained precision (RSD $<20 \%$ ). 
Anaerobic biomass samples with and without the addition of LCFA were also analysed to test for interferences of the solid biological matrix. Two different structure types of biomass, granular (biomass $G$ ) and suspended (biomass S2), were tested. No LCFA were detected in the granular biomass (assay $11 \mathrm{~A}(\mathrm{~s})$ ), whereas in the suspended biomass (assay 12A(s)) a total LCFA content of $18 \mathrm{mg} / \mathrm{gTS}$ was found. The individual LCFA contents present in this biomass were discounted in the experiments performed with the biomass samples fortified at individual LCFA amounts of about $1 \mathrm{mg}$. In these experiments, LCFA mean recoveries above 93\%, with RSD $<11 \%$, were attained for both biomass types. As previously found for the biological liquid matrix, no interference of both biological solid matrices in the LCFA analysis was observed.

\subsection{Application of the method to monitor anaerobic digestion of lipids}

The proposed method was applied to monitor LCFA degradation/accumulation in an anaerobic CSTR reactor treating dairy cow manure, when submitted to pulses of an oily effluent from a can fish processing industry. Analysis of the fed wastes revealed that LCFA represented $3 \%$ and $77 \%$ of the COD in the cow manure and in the oily effluent, respectively (Table 6). Previous to the pulses, analysis of the digested manure showed a LCFA reduction of $80 \%$, when compared to the fresh manure. This reduction was identical for all LCFA detected in the analysed samples.

The chromatograms obtained from the LCFA analysis (not shown) displayed a good separation between peaks, indicating that the peak integration was not interfered by the solid matrix, in contrast to the HPLC chromatograms presented by Jarvis and Thiele (1997). In addition, the retention times of the LCFA detected were

Table 6

LCFA content in the reactor feed

\begin{tabular}{lll}
\hline LCFA & Cow manure (mg COD/gTS) & Oily effluent (mg COD/g waste) \\
\hline C14:0 & 3 & 19 \\
C16:0 & 14 & 260 \\
C16:1 & 0 & 27 \\
C18:0 & 25 & 75 \\
C18: 1 & 0 & 891 \\
C18:2 & 0 & 790 \\
\hline
\end{tabular}

in concurrence to the GC chromatogram presented by Procida and Ceccon (2006), for the analysis of free fatty acids in liquid phase of olive mill wastewaters.

Successive pulses of the oily effluent were applied to the reactor on days $123,130,137,144,151$ and 158 . In each applied pulse, the main LCFA fed to the reactor were C18:1 (43.2 $\pm 0.4 \%)$, followed by C18:2 (38.3 $\pm 0.5 \%)$ and C16:0 (12.5 $\pm 0.1 \%$ ) (Table 6). During the pulses trial, no LCFA were detected in the liquid phase collected from the reactor, suggesting a fast accumulation of these compounds into the solid phase. This finding is in accordance with Hanaki et al. (1981) that reported that these compounds could fast adsorb to the biomass, within $24 \mathrm{~h}$. In this study, LCFA accumulation onto the biomass was confirmed by the results obtained from LCFA analysis in the solid matrix collected from the bottom of the reactor. The LCFA detected in this phase were C14:0, C16:0, $\mathrm{C} 18: 0, \mathrm{C} 18: 1$ and C18:2. It was further demonstrated that C16:0 and C18:1 were the main LCFA adsorbed/accumulated onto the sludge, jointly accounting for about $60-100 \%$ of the total LCFA detected in the solid phase (Fig. 1). Along the trial period, a decrease of $\mathrm{C} 18: 1$ in the solid phase was observed, which became more evident in the last two pulses. These data suggests that the conversion of $C 18: 1$, the main LCFA fed to the reactor, by the adapted biomass became faster and more effective along the successive pulses. Conversely, the accumulation of $\mathrm{C} 16: 0$ in the solid phase suggested that degradation of this LCFA, under these conditions, was less effective.

Nevertheless, the specific content of C16:0 accumulating in the last two pulses was relatively low, ranging from 7 to 18 $\mathrm{mgCOD} / \mathrm{gST}$. The presented method for LCFA detection and quantification constitutes a valuable tool to identify key intermediates in the still obscure anaerobic accumulation/degradation of LCFA as was shown in the given example.

\section{Conclusions}

The analytical method reported is based on the extraction and gas chromatography analysis of long chain fatty acids present in solid and liquid samples in anaerobic digesters. Relative standard deviation values lower than $15 \%$ and mean LCFA recoveries above $90 \%$ were obtained. After validation, the usefulness of this method was demonstrated in a cow manure digester receiving pulses of an

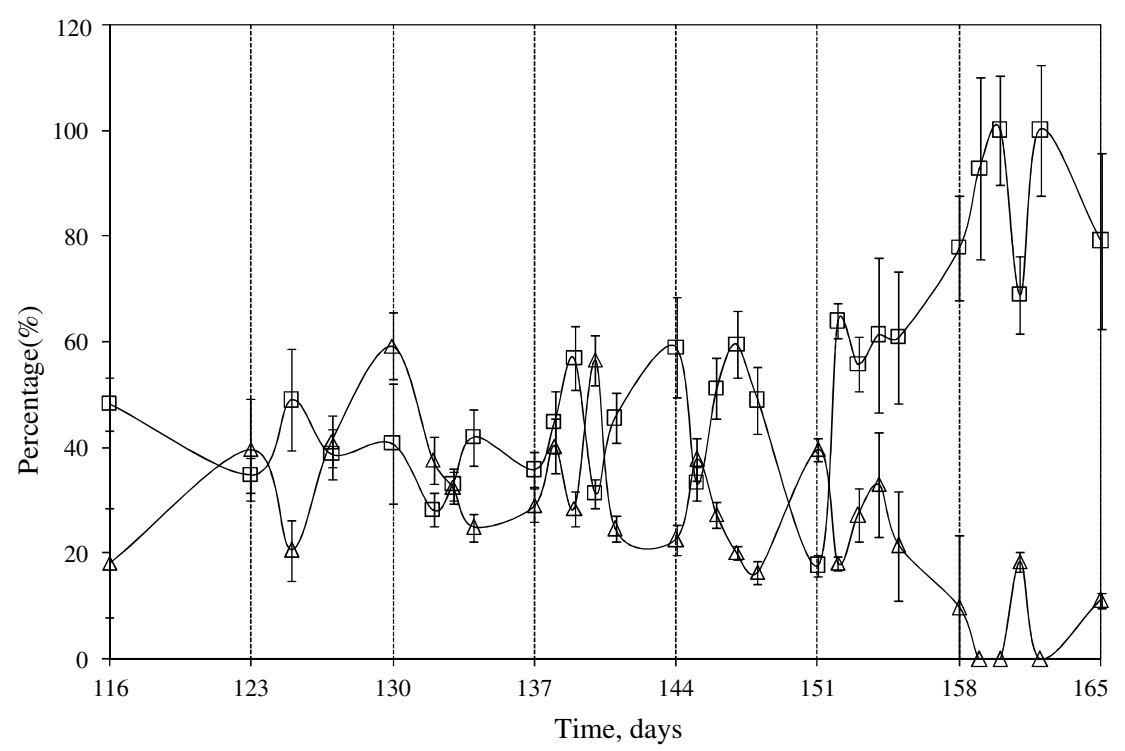

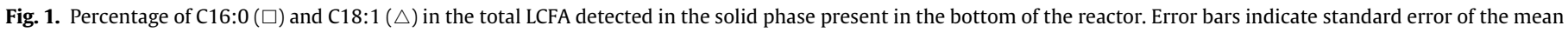
of the replicates. 
industrial effluent containing high lipid content. The conversion of oleic acid (C18:1), the main LCFA fed to the reactor, became faster and more effective along the successive pulses. Conversely, the accumulation of $\mathrm{C} 16: 0$ in the solid phase suggests that degradation of this LCFA, under these conditions, is less effective. The application of this method, as well as the identification of the key intermediates will contribute to a better understanding of LCFA adsorption and degradation processes that occur during the anaerobic digestion of lipids.

\section{Acknowledgements}

The authors would like to acknowledge Madalena Vieira for the technical assistance provided in the gas chromatography analysis. Fundação para a Ciência e Tecnologia (FCT) and Fundo Social Europeu (FSE) are also acknowledged for the financial support given to Lúcia Neves through the project POCTI/CTA/41642/2001 and the grant SFRH/BD/18174/2004, and to M.A. Pereira through the grant SFRH/BPD/30799/2006.

\section{References}

Alves, D.Z., Mota Vieira, J.A., Álvares Pereira, R.M., Pereira, M.A., Novais, J.M., Mota, M., 2001. Effects of lipids and oleic acid on biomass development in anaerobic in fixed bed reactors. Part I: Biofilm growth and activity. Water Res. 35 (1), 255263.

Angelidaki, I., Ahring, B.K., 1992. Effects of free long-chain fatty acids on thermophilic anaerobic digestion. Appl. Microbiol. Biotechnol. 37 (6), 808-812.

APHA, AWWA, WPCF, 1989. Standard Methods for the Examination of Water and Wastewater, 17th ed. American Public Health Association, Washington, DC.

Bligh, E.G., Dyer, W.J., 1959. A rapid method of total lipid extraction and purification. Can. J. Biochem. Physiol. 37, 911-917.

Castillo, M.A., Castells, R.C., 2001. Initial Evaluation performance of chromatographic methods using replicates at multiple concentrations. J. Chromatogr. A 921, 121-133.

Caulcutt, R., Boddy, R., 1983. Statistics for Analytical Chemists, first ed. Chapman and Hall, UK.

Fernández, A., Sánchez, A., Font, X., 2005. Anaerobic co-digestion of a simulated organic fraction of municipal solid wastes and fats of animal and vegetable origin. Biochem. Eng. J. 26, 22-28.
Gebauer, R., Eikebrokk, B., 2006. Mesophilic anaerobic treatment of sludge from salmon smolt hatching. Bioresource Technol. 97, 389-2401.

Hanaki, K., Matsuo, T., Nagase, M., 1981. Mechanisms of inhibition caused by long chain fatty acids in anaerobic digestion process. Biotechnol. Bioeng. 23, 15911610.

Hwu, C.-S., Donlon, B., Lettinga, G., 1996. Comparative toxicity of long-chain fatty acids to anaerobic sludge from various origins. Water Sci. Technol. 34 (5-6), 351-358.

Hwu, C.-S., Tsung, S.-K., Yuan, C.-Y., Kulik, Z., Lettinga, G., 1998. Biosorption of long chain fatty acids in UASB treatment process. Water Res. 32 (5), 1571-1579.

Jarvis, G.N., Thiele, J.H., 1997. High-performance liquid chromatographic analysis of free long chain fatty acids produced during lipolysis by anaerobic digestor sludge. J. Chromatogr. A 760, 271-277.

Kaluzny, M.A., Duncan, L.A., Merritt, M.V., Epps, D.E., 1985. Rapid separation of lipid classes in high yield and purity bonded phase columns. J. Lipid Res. 26, 135140.

Koster, I.W., Cramer, A., 1987. Inhibition of methanoghenesis from acetate in granular sludge by long-chain fatty acids. Appl. Environ. Microbiol. 53 (2), $403-$ 409.

Lalman, J.A., Bagley, D.M., 2000. Anaerobic degradation and inhibitory effects on linoleic acid. Water Res. 34 (17), 4220-4228.

Lalman, J.A., Bagley, D.M., 2001. Anaerobic degradation and methanogenic inhibitory effects of oleic and stearic acids. Water Res. 35 (12), 2975-2983.

Lalman, J.A., Bagley, D.M., 2002. Effects of C18 long chain fatty acids on glucose, butyrate and hydrogen degradation. Water Res. 36 (13), 3307-3313.

Lalman, J.A., Bagley, D.M., 2004. Extracting long-chain fatty acids from a fermentation medium. J. Am. Oil Chem. Soc. 81 (2), 105-110.

Miller, J.C., Miller, J.N., 1993. Statistics for Analytical Chemistry, third ed. Ellis Horwood Limited, Great Britain.

Pereira, M.A., Souza, D.Z., Mota, M., Alves, M.M., 2004. Mineralization of LCFA associated to anaerobic sludge: kinetics, enhancement of methanogenic activity and effect of VFA. Biotechnol. Bioeng. 88 (4), 502-511.

Pereira, M.A., Pires, O.C. Mota, M., Alves, M.M., 2005. Anaerobic biodegradation of oleic and palmitic acids: evidence of mass transfer limitations caused by long chain fatty acid accumulation onto anaerobic sludge. Biotechnol. Bioeng. 92 (1), 15-23.

Procida, G., Ceccon, L., 2006. Gas chromatographic determination of free fatty acids in olive mill waste waters. Anal. Chim. Acta 561, 103-106.

Rinzema, A., Boone, M., Van Knippenberg, K., Lettinga, G., 1994. Bactericidal effect of long chain fatty acids in anaerobic digestion. Water Environ. Res. 66, 40-49.

Shah, V.P., Midha, K.K., Dighe, S., McGilveray, I.J., Skelly, J.P., Yacobi, A., Layloff, T., Viswanathan, C.T., Cook, C.E., McDowall, R.D., Pittman, K.A., Spector, S., 1992 Analytical methods validation: bioavailability, bioequivalence, and pharmacokinetic studies. J. Pharm. Sci. 81, 309-312.

Shin, H.-S., Kim, S.-H., Lee, C.-Y., Nam, S.-Y., 2003. Inhibitory effects of long chain fatty acids on VFA degradation and $\beta$-oxidation. Water Sci. Technol. 47 (10) 139-146. 